\title{
Mental health care - a public health priority in South Africa
}

\author{
JC Meyer, M Matlala, A Chigome
}

Division of Public Health Pharmacy and Management, School of Pharmacy, Sefako Makgatho Health Sciences University, South Africa Corresponding author, email: hannelie.meyer@smu.ac.za

Mental health is an integral part of health and it includes an individual's emotional, psychological and social well-being. Mental illness remains underreported and underdiagnosed, particularly in low- and middle-income countries, including South Africa. South Africa carries a huge burden of mental illnesses with the most prevalent being anxiety disorders, substance abuse disorders, mood disorders and depression. People with mental health conditions often face neglect in the health system as well as stigma and discrimination. This has resulted in poor health outcomes, isolation and high suicide rates, including amongst adolescents. The South African National Mental Health Policy Framework and Strategic Plan (2013-2020) aims to integrate mental health into the health system to provide quality mental health services that are accessible, equitable and comprehensive, particularly for community-based mental health. This article provides an overview of mental health care in South Africa, highlighting its public health importance.

Keywords: mental illness, stigma, suicide, management of mental disorders, adolescents, public health

\section{Introduction}

From the World Health Organization's (WHO) definition of mental health, as "a state of well-being in which every individual realises his or her own potential, can cope with the normal stresses of life, can work productively and fruitfully, and is able to make a contribution to his or her community", it is clear that mental health is not merely the absence of illness or disease, with an impact on the individual as well as the population. ${ }^{1}$ The importance of mental health is recognised globally and clearly reflected in the United Nations' Sustainable Development Goals, for the post2015 agenda. $^{2}$

Mental health disorders share common features with the major non-communicable diseases as well as infectious diseases such as HIV/AIDS and tuberculosis, all being chronic diseases, often co-occurring and requiring continuous management and monitoring. ${ }^{3}$ The $\mathrm{WHO}$ therefore recommends an integrated healthcare system, catering for people's overall healthcare needs, as an efficient way of preventing and managing mental disorders and other chronic diseases. ${ }^{3}$

Over the last two decades, South Africa has taken a public health approach towards better mental health care, firstly with the reform of the Mental Health Care Act (17 of 2002), emphasising the human rights of patients. ${ }^{4,5}$ Secondly, in line with WHO recommendations and to reduce the burden of untreated mental health conditions, South Africa developed a National Mental Health Policy Framework and Strategic Plan 2013-2020, ${ }^{6}$ aimed at the integration of mental health care into a comprehensive primary health care (PHC) approach. ${ }^{4,5}$ Currently, evidence of successful implementation of this policy with integration of mental health is still limited.? In 2017, nearly 150 patients with mental health illness died at unlicensed facilities after being moved from the Life Esidimeni Hospital. ${ }^{8}$

\section{Prevalence of mental disorders in adults}

In 2016, an estimated 1.1 billion people were living with mental health and substance abuse disorders in all but four countries worldwide, of which major depressive disorders ranked amongst the top ten causes of ill health. ${ }^{9}$ The prevalence of mental health disorders is the highest in low- and middle-income countries such as South Africa, ${ }^{10}$ attributed to conflict and trauma, hunger and poverty, poor access to health and social care, and social inequality. ${ }^{11}$ Notwithstanding this high prevalence, these countries spend less than $3 \%$ of their health budgets on mental health care, even though mental disorders cause $25.5 \%$ of the years lived with disability. 3,12 Therefore, the social determinants of mental health cannot be disregarded. ${ }^{13,14}$

In South Africa, neuropsychiatric disorders are ranked third in their contribution to the burden of disease after HIV/AIDS and other infectious diseases. ${ }^{6}$ Prevalence data on mental health in South Africa are limited and date back to the 2004 South African Stress and Health Survey (SASH), reporting a 16.5\% 12-month prevalence and $30.3 \%$ lifetime prevalence of common mental disorders among adults. ${ }^{15}$ Anxiety disorder (15.8\%) was the most prevalent class of lifetime mental disorders, followed by substance use disorder (13.3\%) and mood disorders (9.8\%). ${ }^{15}$ The 
prevalence of post-traumatic stress disorder (PTSD) in patients attending PHC clinics in South Africa was as high as $19.9 \%$ in the period 2003-2004. ${ }^{16}$ During the same period, females were 1.75 times more likely to be diagnosed with major depressive disorder than males, ${ }^{17}$ while males were at an increased risk of developing substance-use disorders. ${ }^{17}$

\section{Brief overview of the most common mental disorders}

Each mental disorder has its own set of specific symptoms, but there are general signs of mental illness. Common early signs of mental disorders are summarised in Box I. ${ }^{18,19}$

\section{Box I. Early signs of mental disorders ${ }^{18,19}$}

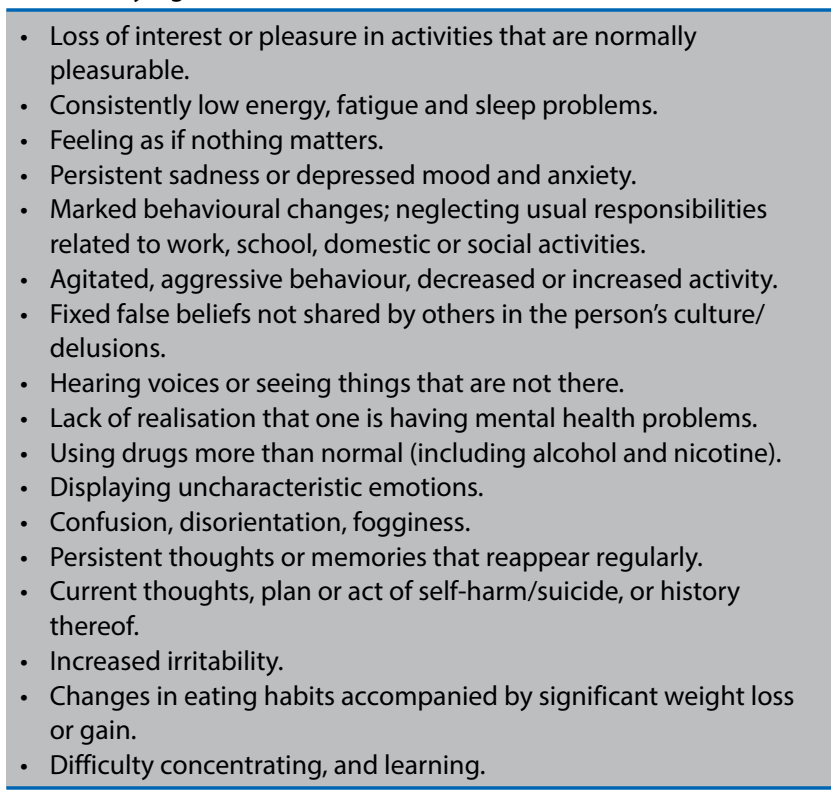

Post-traumatic stress disorder (PTSD) is classified as an anxiety disorder, characterised by recurrent intrusive recollections of an overwhelming traumatic event. ${ }^{20}$ This can occur after somebody has been through a traumatic event, either experienced or witnessed. ${ }^{21}$ The pathophysiology of PTSD is incompletely understood, ${ }^{20}$ although neuroendocrine studies have linked it to abnormalities occurring in pre-trauma, during trauma and post-trauma. Various neurotransmitters may be involved in the pathophysiology, such as serotonin, norepinephrine and glutamate, which are mainly involved in the processing of emotional and somatic contents of the amygdala. ${ }^{21}$

Generalised anxiety disorder is a distressing, unpleasant emotional state of nervousness and unease, often accompanied by physical changes and behaviours similar to those caused by fear. ${ }^{20}$ Generalised anxiety disorder is characterised by excessive, almost daily anxiety and worry about activities or events occurring over a period of six months or longer. ${ }^{20}$ Generalised anxiety disorder may be associated with PTSD, increased rates of substance abuse and obsessive-compulsive disorder. ${ }^{22}$ It is also linked to a significant degree of functional impairment (similar to major depression), poor cardiovascular health and coronary heart disease. ${ }^{22}$ Neurotransmitters such as norepinephrine, $\gamma$-aminobutyric acid, serotonin, corticotropin-releasing factor, and cholecystokinin have been linked to the modulation of normal and pathologic anxiety states. ${ }^{23}$
Major depressive disorder is also known as unipolar depression. Episodes of major depression occur in both major depressive disorder and in bipolar disorder. However, in the case of bipolar disorder, patients have a lifetime history of manic/hypomanic episodes whereas patients with unipolar major depression do not. ${ }^{24}$ The exact cause of depression remains unknown but it has been linked to heredity factors, changes in neurotransmitters such as NE, 5-HT, and dopamine, altered endocrine function and psychosocial factors. $^{25}$

Bipolar disorder is a mood disorder, characterised by episodes of mania, hypomania, and major depression. ${ }^{24}$ The subtypes of bipolar disorder include bipolar I and bipolar II. Patients with bipolar I disorder experience manic episodes and nearly always experience major depressive and hypomanic episodes. Bipolar II disorder is marked by at least one hypomanic episode, at least one major depressive episode, and the absence of manic episodes. $^{24}$

Manic episodes involve clinically significant changes in mood, energy, activity, behaviour, sleep, and cognition. Manic speech is typically loud, pressured or accelerated, and difficult to interrupt, and may be accompanied by jokes, singing, clanging and dramatic signals. The duration of manic episodes can range from weeks to months. ${ }^{20,24}$ Manic patients could also be involved in various high-risk and pleasurable activities including promiscuous sexual activities and dangerous sports. ${ }^{20}$

Hypomanic episodes are characterised by changes in mood, energy, activity, behaviour, sleep, and cognition that are similar but less severe than those of mania. Hypomanic speech can be loud and rapid, but generally easier to interrupt than manic speech. ${ }^{24}$

\section{Mental health disorders in adolescents}

Mental health amongst adolescents is common, with approximately $20 \%$ of children and adolescents having a mental health disorder. ${ }^{26}$ Going through adolescence, a time during which many psychosocial and physiological changes take place, often results in huge stress levels and subsequent mental health disorders. ${ }^{27}$ About half of mental health or drug abuse problems occur around the age of 14 years. ${ }^{26}$ Mental illness amongst adolescents is often associated with poor academic achievement, substance use, violence, suicide, pregnancy and an increased risk of psychopathology later in adulthood. ${ }^{28}$ Psychosocial factors also play a role such as abuse, neglect, bereavement, family conflict, bullying and stressful life events. ${ }^{28}$ In South Africa, one in five high school learners has tried or considered to take their own life at some point and $9 \%$ of young adult deaths are as a result of suicide. ${ }^{29}$ All these factors contribute to the high disease burden associated with mental health illness amongst adolescents. ${ }^{28}$

Diagnosis of mental illness in adolescents can be more challenging, as compared to adults, despite fairly similar diagnostic criteria for both groups..$^{30}$ Common emotional and behavioural changes as part of normal development, could make it difficult to distinguish from the mental illness..$^{30}$ Most adolescents are not able to access health services independently 
and are accompanied by a caregiver. This could result in reluctance to engage with the practitioner, fear of disclosing personal information to the caregiver, or fear of stigmatisation by others. ${ }^{30}$

The mental illness treatment plan for adolescents should be multimodal, including family and school involvement, the use of psycho-education, pharmacological and psychosocial interventions. ${ }^{28}$ Various factors should be considered when medication is prescribed, including the severity of the psychiatric disorder, past psychiatric history, family history, medical history and patient and family preference. Polypharmacy should be avoided and the appropriate dosage with slow titration is important. Being adequately prepared and equipped with knowledge to meet the specific needs of adolescents with mental health challenges, is one step in the right direction of ensuring the wellbeing of this group of young people in whom mental illness is poorly detected and sub-optimally treated. ${ }^{27}$

\section{Suicide due to mental health disorders}

Suicide is a global health challenge with economic and societal consequences. ${ }^{31-33}$ Over 800000 suicide-related deaths occurred in 2012 globally with suicide being the second leading cause of death for young people aged between 15 and 29 years. ${ }^{34}$ The suicide burden is highest in low- to middle-income countries, despite underreporting of suicide cases, due to cultural, social and religious stigma. ${ }^{31-34}$ Approximately $90 \%$ of all suicides are attributed to psychiatric illness such as mood disorders, personality disorders, alcohol and substance abuse disorders. ${ }^{31}$ Severe mental disorders are associated with an increased risk of suicide and suicide attempts in comparison to the general population. ${ }^{31-33}$ Suicide is 15 times more likely in bipolar disorder patients compared to the general population, with as many as $7-15 \%$ of all bipolar sufferers committing suicide. ${ }^{35}$

Suicide prevention interventions should be comprehensive, collaborative and take into consideration the complexity of mental conditions. ${ }^{34,36}$ Interventions may include training for health professionals and the community to raise public awareness and reduce stigma. ${ }^{29}$ Suicide prevention strategies should be implemented at population and individual levels and can include restricting access to suicide means (medication, firearms, pesticides, toxic substances), introducing policies that limit alcohol intake, responsible media guidelines and follow-up care for people who attempted suicide. ${ }^{34,37}$ Early diagnosis and treatment of mental disorders should be prioritised as well as strengthening of PHC facilities as primary care providers have frequent interaction with suicidal patients. ${ }^{36}$

\section{Stigma and discrimination associated with mental health disorders}

People with mental health conditions commonly face stigma and discrimination, which impact negatively on their lives and are associated with poor mental health prognosis and increased premature mortality. ${ }^{38,39}$ Stigma associated with mental illness and consequent discrimination is considered the cause of worse outcomes than the actual mental illnesses (or barriers to improvement). ${ }^{39}$ Stigma and discrimination against people with mental illnesses are significant contributors to self-harm and suicide attempts amongst this group. ${ }^{36,40}$ Evidence has shown that individuals who felt excluded from social and work interactions due to mental health issues, were likely to attempt committing suicide. ${ }^{36}$ Stigma and discrimination do not only affect people with mental disorders but also their families and caregivers. ${ }^{38,39}$

Structured interventions that address national and cultural disparities should be identified to reduce stigma towards mentally ill people. ${ }^{41,42}$ Media campaigns that address stereotypes, cultural barriers, biases and myths should be designed to address specific stigmatising behaviours among specific target populations. ${ }^{42,43}$ Platforms that encourage people with mental disorders to share their experiences may be useful in promoting social integration and addressing social discrimination. ${ }^{43}$ Initiatives that increase health providers' awareness and promote diagnosis and treatment of mental disorders could reduce both stigma and suicide associated with stigma. ${ }^{38}$ Integration of mental health services into PHC in South Africa is a necessary step towards addressing stigma and discrimination of mentally ill people. ${ }^{42}$ Counselling of affected families should address how to deal with the different levels of stigma. ${ }^{42}$

\section{Management of mental disorders}

The successful management of mental disorders is complex, with integrated treatment plans, including pharmacological, psychological and social interventions. ${ }^{44}$ While psychosocial interventions are important in promoting recovery and improving quality of life, pharmacological treatment remains the mainstay of therapy. ${ }^{44}$

Pharmacological management of mental disorders is briefly summarised in Table I.

Psychological interventions focus on the individual and may include cognitive behaviour therapy, psychoeducation, family focused education and supportive psychotherapy. $17,35,44$ Exposure-based, trauma-focused cognitive behaviour therapy is one of the first-line therapies in the management of PTSD. ${ }^{44}$

Social interventions aim to improve adherence to treatment, reduce symptoms and limit behaviour that may result in injury. Social interventions may include social skills training, appropriate housing, supported employment and adaptation to life in the community. ${ }^{44}$

Physical interventions include electroconvulsive therapy (ECT), which is a treatment option available to patients with severe depression who present with psychotic features. ${ }^{17}$ In patients with bipolar mood disorder, ECT in combination with mood stabilisers should be considered if symptoms and/or behavioural disturbances are severe or protracted..$^{35}$ 
Table I. Summary of pharmacological treatment options for mental disorders ${ }^{16,35,44}$

\begin{tabular}{|c|c|}
\hline Mental disorder & $\begin{array}{c}\text { Pharmacological management } \\
\text { options }\end{array}$ \\
\hline $\begin{array}{l}\text { Major depressive disorder } \\
\text { Post-traumatic stress } \\
\text { disorder during } \\
\text { pregnancy }\end{array}$ & $\begin{array}{l}\text { Tricyclic and tetracyclic anti-depressants } \\
\text { Tricyclics: } \\
\text { - Amitriptyline } \\
\text { - Imipramine } \\
\text { Tetracyclics: } \\
\text { - Amoxapine } \\
\text { - Maprotiline }\end{array}$ \\
\hline $\begin{array}{l}\text { Major depressive disorder } \\
\text { Bipolar disorder } \\
\text { Anxiety } \\
\text { Post-traumatic stress } \\
\text { disorder }\end{array}$ & $\begin{array}{l}\text { Serotonin reuptake inhibitors } \\
\text { - Citalopram } \\
\text { - Escitalopram } \\
\text { - Fluoxetine } \\
\text { - Fluvoxamine } \\
\text { - Paroxetine } \\
\text { - Sertraline } \\
\text { Anticonvulsants } \\
\text { - Pregabalin }\end{array}$ \\
\hline $\begin{array}{l}\text { Major depressive disorder } \\
\text { Post-traumatic stress } \\
\text { disorder }\end{array}$ & $\begin{array}{l}\text { Serotonin-norepinephrine reuptake } \\
\text { inhibitors } \\
\text { - Venlafaxine } \\
\text { - Duloxetine }\end{array}$ \\
\hline $\begin{array}{l}\text { Major depressive disorder } \\
\text { Bipolar disorder }\end{array}$ & $\begin{array}{l}\text { Norepinephrine-dopamine reuptake } \\
\text { inhibitors (NDRIs) } \\
\text { - Bupropion } \\
\text { Atypical antipsychotics: } \\
\text { - Aripiprazole } \\
\text { - Olanzapine } \\
\text { - Quetiapine } \\
\text { - Clozapine }\end{array}$ \\
\hline Major depressive disorder & $\begin{array}{l}\text { Monoamine oxidase inhibitors } \\
\text { - Tranylcypromine } \\
\text { - Phenelzine } \\
\text { - Moclobemide }\end{array}$ \\
\hline Bipolar disorder, anxiety & $\begin{array}{l}\text { Anxiolytics } \\
\text { Benzodiazepines: } \\
\text { - Lorazepam } \\
\text { - Clonazepam }\end{array}$ \\
\hline Bipolar disorder & $\begin{array}{l}\text { Mood stabilisers } \\
\text { Anticonvulsants: } \\
\text { - Lamotrigine* } \\
\text { - Carbamazepine* } \\
\text { - Gabapentin } \\
\text { Other } \\
\text { - Lithium }\end{array}$ \\
\hline
\end{tabular}

*Limited efficacy in the prevention of mania in bipolar II depression

\section{Integration of mental health care into primary health care}

The South African Mental Health Policy aims to integrate mental health care into PHC by introducing several strategies such as scaling up decentralised primary mental health services, increasing public awareness regarding mental health, promoting mental health in the South African population, empowering local communities to participate in promoting mental wellbeing and recovery within the community, and ensuring that the planning and provision of health services are evidence-based. ${ }^{5}$

The Lancet Commission (2018) has adopted a staging approach for the classification and treatment of mental disorders that can be used to achieve the strategies outlined by the South African Policy Framework. ${ }^{45}$ The approach is summarised in Figure 1 and is in line with the policy as it recognises the involvement of the community and all healthcare stakeholders in the management of mental health. ${ }^{45}$ Staging implies that with appropriate treatment and care, along with addressing relevant risk factors or strengthening environments that promote mental health at population level, mental health care is modifiable. ${ }^{35}$

In order to incorporate mental health into comprehensive PHC, the South African National Mental Health Policy Framework and Strategic Plan 2013-2020 aims to scale up decentralised integrated PHC services, which will include community-based care, PHC clinic care and district hospital-level care. ${ }^{5}$

General practitioners (GPs) at PHC level are in the ideal position to potentially fulfil several important roles in the care of mental health patients. They are accessible to patients and often the initial clinical contact for the patient seeking treatment. ${ }^{46}$ This is an ideal opportunity for GPs to provide screening services and risk assessment services for common mental health disorders such as depression. ${ }^{47}$ They can do first stage screening for mental health conditions, through basic assessment of mental health. ${ }^{48}$ This includes a brief interview inquiring about mental health symptoms, family history of mental illness and any other factors that might be causing anxiety or stress, a physical examination as well as some laboratory tests. Special attention should be paid to vulnerable populations, such as patients with intellectual disabilities, who are prone to mental illness. ${ }^{6}$

In addition to pharmacological treatment, depending on the patient's needs, GPs can refer patients to a counsellor, psychologist, psychiatrist or other mental health professional. They have the opportunity to connect patients with psychosocial services and specialised care providers. In addition, psychiatric services alone can neither meet the demand for care, nor provide it cost-effectively, hence GPs are increasingly called upon to provide appropriate care. ${ }^{49}$ Providing these kinds of services can enable GPs to identify patients with a suspected mental health problem, refer them for further treatment and act as the link between different areas of care. ${ }^{45,47}$ Furthermore, PHC practitioners can play an important role in mental health awareness and reducing stigma associated with mental health disorders. ${ }^{6}$

Sub-optimal adherence to medicines used in the treatment of mental health disorders in particular, remains a challenge, and side-effects from antipsychotic medicines are known to have a negative impact on adherence rates. ${ }^{45,47}$ Additionally, patients on multiple antipsychotic medicines, and those on other chronic medicines as well, may also experience more side-effects as compared to those on monotherapy. ${ }^{45}$ To ensure patient safety, the GP can work with the pharmacist, who can provide counselling on the safe and effective use of medication, monitor adverse drug reactions and prevent possible medication-related problems..$^{50}$

Because of the significant short- and long-term morbidity associated with adolescent mental illness, creating awareness, improved screening, detection and treatment of mental illness is a priority..$^{30}$ This can be achieved through an integrated healthcare system, providing medical and mental health care at primary and secondary level. ${ }^{30}$ 


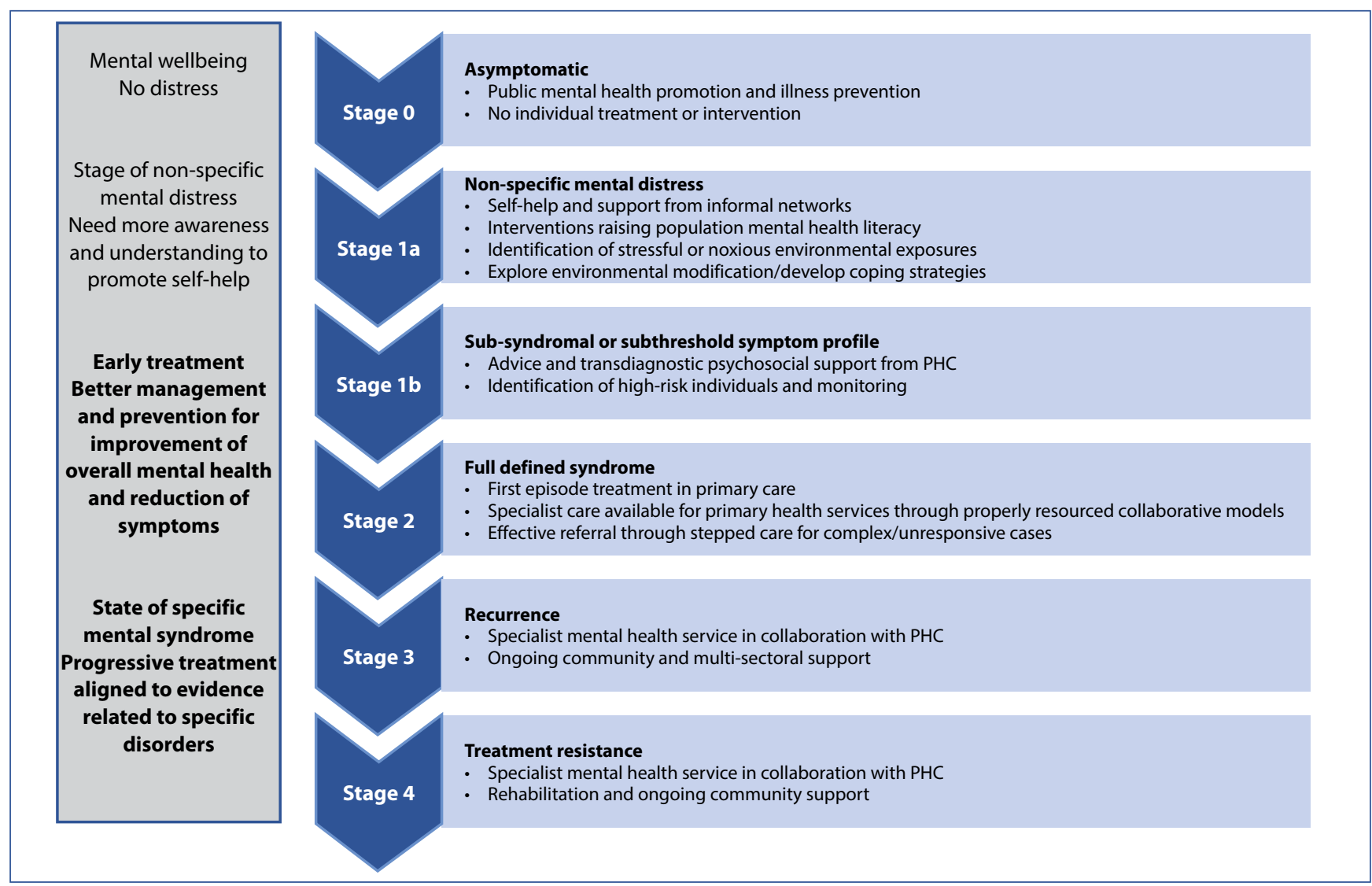

Figure 1. Staging of mental disorders ${ }^{45}$

Box II. Patients with mental health challenges - where to get help

SA Depression and Anxiety Group (SADAG)

Website: http://www.sadag.org

Tel: 0112344837 (08h00 - 20h00, 7days a week)

Suicidal emergency line: 0800567567

24hr helpline: 0800121314

\section{LifeLine}

Website: www.lifelinesa.co.za

Helpline (24hrs): 0861322322

\section{Suicide.org}

Website: http://www.suicide.org/

\section{Conclusion}

Mental health disorders remain neglected within the healthcare system, yet they share common features of other chronic conditions and should therefore be integrated into the chronic disease model. Universal health coverage potentially provides an opportunity for addressing neglected mental health disorders in all tiers of healthcare provision. As South Africa is moving towards universal health coverage, with the introduction of the National Health Insurance, recognition of mental health care as an integral part of the healthcare system with financial protection for community-based mental health services will be essential. ${ }^{51}$ Interventions that promote public awareness should be prioritised to address prejudice against mental disorders. General practitioners can play an important role in the identification of mental health disorders, intervention and referral, as they are easily accessible to the public and often the patient's first point of contact with the healthcare system.

\section{References}

1. World Health Organization (WHO). Mental health action plan 2013-2020. 2013. Available from: http://www.who.int/mental_health/publications/action_plan/ en/ (Accessed 11/10/2019).

2. Le Blanc $D$. Towards integration at last? The sustainable development goals as a network of targets. Sustainable Development. 2015. May; 23(3):176-87.

3. World Health Organization (WHO) and Calouste Gulbenkian Foundation. Integrating the response to mental disorders and other chronic diseases in health care systems. Geneva, WHO. 2014.

4. Republic of South Africa. Mental Health Act, 17 of 2002. Available from: https:// www.gov.za/documents/mental-health-care-act (Accessed 11/10/2019).

5. Schneider M, Baron E, Breuer E, Docrat $S$, et al. Integrating mental health into South Africa's health system: Current status and way forward. In: Padarath A, King J, Mackie E, Casciola J, editors. South African Health Review 2016. Durban: Health Systems Trust; 2016. Available from: http://www.hst.org.za/publications/ south-african-health-review-2016 (Accessed 11/10/2019).

6. Department of Health, National Mental Health Policy Framework and Strategic Plan 2013-2020. Department of Health. Pretoria, South Africa. 2013. Available from: https://www.health-e.org.za/2014/10/23/policy-national-mental-healthpolicy-framework-strategic-plan-2013-2020/ (Accessed 11/10/2019).

7. Docrat S, Lund C, Chisholm D. Sustainable financing options for mental health care in South Africa: findings from a situation analysis and key informant interviews. Int J Ment Health Syst. 2019 Jan 21;13:4. doi: 10.1186/s13033-0190260-4. eCollection 2019.

8. South African Human Rights Commission. Report of the National Investigative Hearing Into the Status of Mental Health Care in South Africa. 14 and 13 November 2017. Available from: https:/www.sahrc.org.za/home/21/files/ SAHRC\%20Mental\%20Health\%20Report\%20Final\%2025032019.pdf

9. Vos T, Abajobir AA, Abate $\mathrm{KH}$, Abbafati $C$, et al. Global, regional, and national incidence, prevalence, and years lived with disability for 328 diseases and injuries for 195 countries, 1990-2016: a systematic analysis for the Global Burden of Disease Study 2016. The Lancet. 2017 Sep 16;390(10100):1211-59. DOl:https:// doi.org/10.1016/S0140-6736(17)32154-2.

10. Wang PS, Aguilar-Gaxiola S, Alonso J, Angermeyer MC, et al. Use of mental health services for anxiety, mood, and substance disorders in 17 countries in the WHO world mental health surveys. The Lancet. 2007 Sep 8; 370 (9590):841-50. DOl:https://doi.org/10.1016/S0140-6736(07)61414-7. 
11. Kohrt BA, Hruschka DJ, Worthman CM, Kunz RD, et al. Political violence and mental health in Nepal: prospective study. Br J Psychiatry. 2012. Oct; 201(4):26875. doi: 10.1192/bjp.bp.111.096222.

12. World Health Organization (WHO) and Calouste Gulbenkian Foundation. Social determinants of World Health Organization. WHO mental health atlas 2011. Geneva, WHO. 2011.

13. Manderscheid RW, Ryff CD, Freeman EJ, McKnight-Eily LR, et al. Evolving definitions of mental illness and wellness. Preventing chronic disease. 2010 Jan;7(1). Available from: http://www.cdc.gov/pcd/issues/2010/jan/09_0124.htm (Accessed 11/10/2019).

14. World Health Organization (WHO) and Calouste Gulbenkian Foundation. Social determinants of mental health. Geneva, WHO. 2014

15. Herman AA, Stein DJ, Seedat S, Heeringa SG, et al. The South African Stress and Health (SASH) study: 12-month and lifetime prevalence of common mental disorders. S Afr Med J. 2009 May; 99(5 Pt 2):339-44.

16. Seedat S. Post-traumatic stress disorder: The South African Society of Psychiatrists (SASOP) Treatment Guidelines for Psychiatric Disorders. S Afr J Psychiatr. 2013 Jan 1;19(3):187-91.

17. Grobler D. Major depressive disorder. The South African Society of Psychiatrists (SASOP) Treatment Guidelines for Psychiatric Disorders: Major depressive disorder. S Afr J Psychiatr. 2013 Jan 1;19(3):157-163.

18. World Health Organization (WHO). mhGAP intervention guide for mental, neurological and substance use disorders in non-specialized health settings: mental health Gap Action Programme (mhGAP). Version 2.0. 2016. Available from: https://www.who.int/mental_health/mhgap/mhGAP_intervention_ guide_02/en/ (Accessed 11/10/2019).

19. Brenner GM, Stevens C. Pharmacology. 4th edition. Philadelphia: WB Saunders Company. 2013.

20. Porter SR, Kaplan JL. The Merck Manual of Diagnosis and Therapy. 19th edition. 2011. Whitehouse station: Merck Sharp \& Dohme Corp.

21. Kirkwood CK, Melton ST, Wells BG. Posttraumatic stress disorder and obsessive-compulsive disorder. In: DiPiro JT, Talbert RL, Yee GC, Matzke GR, et al. Pharmacotherapy: A Pathophysiologic Approach, 10th ed. New York, NY: McGraw-Hill. 2017

22. Baldwin D, Stein MB, Hermann R. Generalized anxiety disorder in adults: Epidemiology, pathogenesis, clinical manifestations, course, assessment, and diagnosis. In: UpToDate, Stein MB (Ed), UpToDate, Waltham, MA. 2019. Available from: https://www.uptodate.com/contents/generalized-anxiety-disorder-inadults-epidemiology-pathogenesis-clinical-manifestations-course-assessmentand-diagnosis?search=Generalized $\% 20$ anxiety $\% 20$ disorder $\% 20 \mathrm{in} \% 20$ adults:\%20Epidemiology,\%20pathogenesis,\%20clinical\%20manifestations, $\% 20$ course,\%20assessment,\%20and\%20diagnosis\&source=search_result\&selectedTi tle=1 150\&usage_type=default\&display_rank=1 (Accessed 11/10/2019).

23. Melton ST, Kirkwood CK. Anxiety disorders: Generalized anxiety, panic, and social anxiety disorders. In: DiPiro JT, Talbert RL, Yee GC, Matzke GR, et al. Pharmacotherapy: A Pathophysiologic Approach, 10th edition. New York, NY: McGraw-Hill. 2017.

24. Suppes T. Bipolar disorder in adults: Clinical features. In: UpToDate, Keck P (Ed), UpToDate, Waltham, MA. 2019. Available from: https://www.uptodate. com/contents/bipolar-disorder-in-adults-clinical-features?search=Bipolar\%20 disorder\%20in\%20adults:\%20Clinical\%20features\&source=search_result \&selec tedTitle=1 150\&usage_type=default\&display_rank=1 (Accessed 11/10/2019).

25. Teter CJ, Kando JC, Wells BG. Chapter 51: Major Depressive Disorder. In: DiPiro JT, Talbert RL, Yee GC, Matzke GR, et al. Pharmacotherapy: A Pathophysiologic Approach, 9th edition. New York, NY: McGraw-Hill. 2014.

26. Kessler RC, Berglund $P$, Demler $O$, et al. Lifetime prevalence and age of onset distributions of DSMIV in the National Comorbidity Survey Replication. Arch Gen Psychiatry 2005;62(6):593-602. DOI:10.1001/archpsyc.62.6.593.

27. Karim QA. Mental health of and substance use by adolescents. Guest Editorial. S Afr Med J 2016;106(6):547. DOI:10.7196/SAMJ.2016.v106i6.11026.

28. Patel V, Flisher AJ, Hetrick S, McGorry P. Mental health of young people: A global public health challenge. Lancet 2007;369:1302-1313.

29. South African Depression and Anxiety Group (SADAG). Top Ten Facts on Teen Suicide. Available from: http://www.sadag.org/index. php?option=com_content\&view=article\&id=2067:top-10-facts-on-teensuicide\&catid=94\&ltemid=132 (Accessed 11/10/2019)

30. Paruk S, Karim E. Update on adolescent mental health. S Afr Med J 2016;106(6):548-550. DOI:10.7196/SAMJ.2016.v106i6.10943.

31. World Health Organization (WHO). Public health action for the prevention of suicide: A framework. 2012. Available from: http://apps.who.int/iris/ bitstream/handle/10665/75166/9789241503570_eng.pdf?sequence=1 (Accessed 11/10/2019).

32. Cassidy F. Risk factors of attempted suicide in bipolar disorder. Suicide Life Threat Behav. 2011 Feb; 41(1):6-11. doi: 10.1111/j.1943278X.2010.00007.

33. Shibre T, Hanlon C, Medhin G, Alem A, et al. A. Suicide and suicide attempts in people with severe mental disorders in Butajira, Ethiopia: 10-year follow-up of a population-based cohort. BMC Psychiatry. 2014 May 23; 14:150. Doi: 10.1186/1471-244X-14-150.

34. World Health Organization (WHO). Preventing suicide: a global imperative. 2014 Available from: http://apps.who.int/iris/bitstream/handle/10665/131056/978924 1564779_eng.pdf?sequence=1 (Accessed 11/10/2019).

35. Colin F. The South African Society of Psychiatrists (SASOP) Treatment Guidelines for Psychiatric Disorder: Bipolar disorder. S Afr J of Psychiatr. 2013 Jan 1;19(3):164-171.

36. Carpiniello B, Pinna F. The reciprocal relationship between suicidality and stigma. Front Psychiatry. 2017 Mar 8; 8:35. doi: 10.3389/fpsyt.2017.00035.

37. Randall JR, Walld R, Finlayson G, Sareen J, et al. Acute risk of suicide and suicide attempts associated with recent diagnosis of mental disorders: a populationbased, propensity score-matched analysis. Can J Psychiatry. 2014 Oct; 59(10):531-8.

38. Oexle N, Ajdacic-Gross V, Kilian R, Müller M, et al. Mental illness stigma, secrecy and suicidal ideation. Epidemiol Psychiatr Sci. 2017 Feb; 26(1):53-60. doi $10.1017 /$ S2045796015001018.

39. Seeman N, Tang S, Brown AD, Ing A. World survey of mental illness stigma. J Affect Disord. 2016 Jan 15; 190:115-21. doi: 10.1016/j.jad.2015.10.011.

40. Farrelly $S$, Jeffery $D$, Rüsch $N$, Williams $P$, et al. The link between mental healthrelated discrimination and suicidality: service user perspectives. Psychol Med. 2015 Jul; 45(10):2013-22. doi: 10.1017/S0033291714003158.

41. Krajewski C, Burazeri G, Brand H. Self-stigma, perceived discrimination and empowerment among people with a mental illness in six countries: Pan European stigma study. Psychiatry Res. 2013 Dec 30; 210(3):1136-46. doi:10.1016/j.psychres.2013.08.013.

42. Egbe CO, Brooke-Sumner C, Kathree T, Selohilwe O, et al. Psychiatric stigma and discrimination in South Africa: perspectives from key stakeholders. BMC Psychiatry. 2014 Jul 4; 14:191. doi: 10.1186/1471-244X-14-191.

43. Knaak S, Mantler E, Szeto A. Mental illness-related stigma in healthcare: Barriers to access and care and evidence-based solutions. In: Healthcare management. Sage CA: Los Angeles, CA: SAGE Publications. 2017 Mar; 30(2):111-116. doi: $10.1177 / 0840470416679413$

44. Swingler D. The South African Society of Psychiatrists (SASOP) Treatment Guidelines for Psychiatric Disorder: Schizophrenia. S Afr J of Psychiatr. 2013 Jan 1;19(3):153-156.

45. Patel V, Saxena S, Lund C, Thornicroft G, et al. The Lancet Commission on global mental health and sustainable development. The Lancet. 2018;392(10157):15531598. doi.org/10.1016/S0140-6736(18)31612-X.

46. Walters P, Tylee A, Goldberg D, Murray RM, et al. Psychiatry in Primary Care. Essential Psychiatry. 4th edition. UK: Cambridge University Press; 2008, 479-497.

47. National Department of Health (NDoH). Adherence Guidelines for HIV, TB and NCDs. Pretoria, Department of Health. February 2016.

48. Motsohi TS, Isaacs AA, Manga N, Le Grange C, et al. Common mental disorders are not diagnosed commonly in community health centres. South African Family Practice, 2015;57:4, 259-260, DOI: 10.1080/20786190.2014.97809.

49. Mykletun A, Knudsen AK, Tangen T, Overland S. General practitioners' opinions on how to improve treatment of mental disorders in primary health care. Interviews with one hundred Norwegian general practitioners. BMC Health Serv Res, 2010:10-35.

50. Independent Community Pharmacist Association (ICPA). Mental health awareness and how your pharmacist can help. 2017. Available from: https:// icpa.co.za/mental-health-awareness-and-how-your-pharmacist-can-help.php (Accessed 11/10/2019).

51. Robertson LJ, CHiliza B, J v Rensburg AB, Talatala M. Towards universal health coverage for people living with mental illness in South Africa. In: Rispel LC Padarath A, editors. South African Health Review 2018. Durban, Health Systems Trust. 2018. Available from: http://www.hst.org.za/publications/Pages/SAHR2018 (Accessed 11/10/2019). 